\begin{tabular}{|c|c|}
\hline Title & Isolation of a simian immunodeficiency virus from a mal brouck (Chlorocebus cynosuros) \\
\hline Author(s) & $\begin{array}{l}\text { Carr, Michael; Kawaguchi, A kira; Sasaki, Michihito; Gonzal ez, Gabriel; Ito, Kimi hito; Thomas, Y uka; Hang'ombe, } \\
\text { Bernard M.; Mweene, A aron S.; Zhao, Guoyan; W ang, David; Orba, Y asuko; I shii, A kihiro; Sawa, Hirofumi }\end{array}$ \\
\hline Citation & $\begin{array}{l}\text { A rchives of virology, 162(2), 543-548 } \\
\text { https://doi.org/10.1007/s00705-016-3129-8 }\end{array}$ \\
\hline Issue Date & 2016-11-01 \\
\hline Doc URL & http:/hdl.handle.net/2115/67556 \\
\hline Rights & The final publication is available at Springer via http://dx.doi.org/10.1007/s00128-016-2011-4 \\
\hline Type & article (author version) \\
\hline File Information & (77624)I solation of a Simian Immunodeficiency V irus from the Malbrouck (Chloroc....pdf \\
\hline
\end{tabular}

Instructions for use 


\section{Isolation of a Simian Immunodeficiency Virus from the Malbrouck (Chlorocebus cynosuros)}

Michael Carr ${ }^{\dagger}$, Akira Kawaguchi ${ }^{\dagger}$, Michihito Sasaki, Gabriel Gonzalez, Kimihito Ito, Yuka Thomas, Bernard M. Hang'ombe, Aaron S. Mweene, Guoyan Zhao, David Wang, Yasuko Orba, Akihiro Ishii, Hirofumi Sawa ${ }^{*}$

Michael Carr, Hirofumi Sawa

Global Station for Zoonosis Control, Global Institution for Collaborative Research and Education (GI-CoRE), Hokkaido University, N20, W10, Kita-ku, Sapporo 001-0020, Japan

Michael Carr

National Virus Reference Laboratory, University College Dublin, Belfield, Dublin 4, Ireland

Akira Kawaguchi, Michihito Sasaki, Yasuko Orba, Hirofumi Sawa

Division of Molecular Pathobiology, Research Center for Zoonosis Control, Hokkaido University, N20, W10, Kita-ku, Sapporo 001-0020, Japan

Gabriel Gonzalez, Kimihito Ito

Division of Bioinformatics, Research Center for Zoonosis Control, Hokkaido University, N20, W10, Kita-ku, Sapporo 001-0020, Japan

Akihiro Ishii, Yuka Thomas

Hokudai Center for Zoonosis Control in Zambia, Research Center for Zoonosis Control, Hokkaido University, Zambia

Bernard M. Hang'ombe

Department of Para-clinical studies, School of Veterinary Medicine, University of Zambia, Zambia

Aaron S. Mweene

Department of Disease Control, School of Veterinary Medicine, University of Zambia, Zambia

Guoyan Zhao

Department of Pathology \& Immunology, Washington University School of Medicine, St. Louis, MO 63110 , USA

David Wang

Molecular Microbiology and Pathology \& Immunology, Washington University School of Medicine, St. Louis, MO 63110, USA

†These authors contributed equally to this work.

*Corresponding author: Phone:+81-11-706-5185, Fax:+81-11-706-7370, e-mail: h-sawa@czc.hokudai.ac.jp

Keywords: Simian immunodeficiency virus, SIV, African green monkey, Zambia, Chlorocebus cynosuros, malbrouck, next generation sequencing, virus discovery. 


\section{Abstract}

To investigate the diversity of simian immunodeficiency viruses (SIVs) among nonhuman primates (NHPs) in Zambia, next generation sequencing was performed to determine the complete genome of a novel SIV recovered by co-culturing African green monkey (AGM) peripheral blood lymphocytes with human CD4 ${ }^{+} \mathrm{T}$-cell lines. We report the first described SIV (SIVagmMAL-ZMB) from the malbrouck (Chlorocebus cynosuros). Prevalence of SIVagmMAL-ZMB was determined by real-time PCR analysis from splenic RNA in 3.2\% (3/94) of AGMs and was undetectable in baboons $(0 / 105)$. SIVagmMAL-ZMB possessed $<80 \%$ nucleotide sequence identity to known SIVs and was basally located to vervet monkey SIV strains in all phylogenies. 
Old World monkeys and great apes are infected with a diversity of simian immunodeficiency viruses (SIVs) in greater than 40 species of nonhuman primates (NHPs) [1]. SIVs segregate largely into host-specific clades and recombination, cross-species transmission events and spread in new hosts has been documented [2, 3]. Phylogenetic analysis of SIVs infecting NHPs in Africa reveals a number of major lineages in great apes: SIVcpz isolated from chimpanzees (Pan troglodytes) and SIVgor from gorillas (Gorilla gorilla) [4-6] and also within Old World monkeys: SIVsm in sooty mangabeys (Cercocebus atys) [7]; SIVmnd-1 in mandrills (Mandrillus sphinx), which clusters phylogenetically with SIVsun in sun-tailed monkeys (Cercopithecus solatus) and SIVlhoest in L'Hoest monkeys (Cercopithecus l'hoesti) [8-10]; SIVsyk in Sykes' monkeys (Cercopithecus albogularis) [11]; SIVcol in colobus monkeys (Colobus guereza) [12, 13] and finally, SIVagm in African green monkeys (AGMs; Chlorocebus spp.) [14-19].

AGMs within the Chlorocebus genus are now divided into six species and a species-specific SIV has been identified from four species: SIVagmSAB from C. sabaeus (green monkey), SIVagmGRI from C. aethiops (grivet), SIVagmTAN in C. tantalus (tantalus) and SIVagmVER in C. pygerythrus (vervet) [14-20]. To date, no SIV has been identified from the rare $C$. djamdjamensis (Bale Mountains vervet) or from the malbrouck $(C$. cynosuros). The territorial range for the malbrouck extends from the Democratic Republic of Congo to Namibia on the Atlantic coast and to Zambia in central southern Africa.

Surveillance of retroviruses in NHPs is vitally important to improve monitoring and attempt to mitigate cross-species transmission of these agents. Although surveillance of simian retroviruses has been performed in a number of African countries [1], there is no previous report of surveillance of the infection rates and diversity of simian retroviruses in Zambia where human contact with NHPs is not uncommon. AGMs (Chlorocebus spp.) and baboons (Papio spp.) are the principal NHPs in rural and, to some extent, in urban regions of Zambia with reports of encounters leading to direct injury [21]. Therefore, we have performed surveillance of SIV from AGMs and baboons collected in Zambia.

Ethical approval was obtained from the then Zambia Wildlife Authority (ZAWA), now the Department of National Parks and Wildlife, Ministry of Tourism and Arts (certificate no. 2604). Blood and splenic tissues were isolated from AGMs (Chlorocebus sp., $\mathrm{n}=94$ ) and baboons (Papio sp., $\mathrm{n}=105$ ) in Mfuwe District in 2008/2009 as previously described [22]. Zambian NHPs were speciated by cytb gene sequencing as previously described [22]. Peripheral blood mononuclear cells (PBMCs) were separated by Ficoll gradient centrifugation. Genomic DNA was extracted from splenic tissue using the QIAamp DNA isolation kit (Qiagen, Valencia, CA, USA) and SIV consensus PCR performed as described [12, 23]. AGM PBMCs were stimulated with concanavalin A $(10 \mu \mathrm{g} / \mathrm{ml})$ for seven days in RPMI 1640 (Sigma Life Sciences, St. Louis, MO, USA) supplemented with $10 \% \mathrm{FBS}$ at $37^{\circ} \mathrm{C} / 5 \% \mathrm{CO}_{2}$. AGM PBMCs were co-cultured with human MOLT-4 CD4 ${ }^{+} \mathrm{T}-$ cells in RPMI 1640 (10\% FBS). Supernatants of MOLT-4 CD4 ${ }^{+}$and M8166 CD4 ${ }^{+}$T-cell sub-cultures were monitored for viral replication by reverse transcriptase colorimetric assay (Roche, Indianapolis, IN, USA) and by RT-PCR employing the Superscript III One-Step RT-PCR System with Platinum Taq DNA polymerase (Invitrogen, Carlsbad, CA, USA): SIV-ZMB.F1: 5'-TGTACAACCCAGTCTCAGTG-3' and SIV-ZMB.R1: 5'TGGAGTTATGGGGATTGCTT-3' and thermocycling conditions: $50^{\circ} \mathrm{C} 30 \mathrm{~min}, 94^{\circ} \mathrm{C} 2 \mathrm{~min} ; 30$ cycles of $94^{\circ} \mathrm{C}$ $15 \mathrm{sec}, 58^{\circ} \mathrm{C} 30 \mathrm{sec}$ and $72^{\circ} \mathrm{C} 80 \mathrm{sec}$.

Human MOLT-4 CD4 $4^{+}$T-cells cultures persistently infected with SIVagmMAL-ZMB were ultracentrifuged at $186000 \mathrm{x}$ g for 2 hours and RNA was extracted with Trizol (Invitrogen, Carlsbad, CA, USA) with cleanup on Direct-zol RNA miniprep columns (Zymo Research, Irvine, CA, USA). cDNA synthesis was performed on $2 \mu \mathrm{g}$ of total RNA using the Primescript cDNA synthesis kit (Takara Bio, Shiga, Japan). Library construction, emulsion PCR, enrichment and 454 sequencing (Roche, Indianapolis, IN, USA) were performed following the manufacturer's instructions. Reads were assembled with CLC Genomics Workbench software (v8.5.1, Qiagen, Aarhus, Denmark). Rapid amplification of cDNA ends (RACE) was performed employing the SMARTer RACE cDNA amplification kit (Clontech, Mountain View, CA, USA) according to the manufacturer's instructions. SIVagmMAL-ZMB RNA was detected by real-time PCR with Fast Virus 1-Step Master Mix (Applied Biosystems, Foster City, CA, USA), $2 \mu$ of splenic RNA extract, 400 nM SIV-ZMB(+) 5'-CTCAGAAAGAGAACATGATGAAAAAGTT-3' 400 nM SIV-ZMB(-) 5'CATCCATTCATAGGGAGGTTCTG-3', 100 nM SIV-ZMB probe 5'-FAM-ACAGCTTAGAGAGAAACMGB-3' with $\beta$-actin as an internal control [24]. Thermocycling parameters were as follows: 1 cycle of $50^{\circ} \mathrm{C} 5$ min and $95^{\circ} \mathrm{C} 20 \mathrm{sec}$ followed by 40 cycles of $95^{\circ} \mathrm{C} 3 \mathrm{sec}$ and $60^{\circ} \mathrm{C} 30 \mathrm{sec}$ on the StepOne plus real-time PCR system (Applied Biosystems, Foster City, CA, USA).

The nucleotide sequences and amino acid sequences were aligned into multiple sequence alignments by MAFFT [25]. Phylogenetic inferences were performed on multiple sequence alignments of amino acid sequences corresponding to the main proteins and nucleotide sequences of whole genomes with MrBayes 3.2 [26] allowing for rate variations between sites modelled with a gamma distributions $(+\Gamma)$ with five categories and percentages of invariable sites $(+\mathrm{I})$.

SIV pol gene fragments were detected in $18.9 \%$ (18/95) of splenic genomic DNA samples from AGMs and $1.9 \%(2 / 105)$ of DNA samples from baboons by SIV consensus PCR screening. In order to isolate a 
replication competent SIV from the NHPs and establish a persistently infected cell line, PBMCs $(\mathrm{n}=50)$ were co-cultured with human MOLT-4 CD4 ${ }^{+}$T-cells. Expression of an SIV was examined by RT-PCR and viral RNA was detectable from human MOLT-4 and M8166 CD4 ${ }^{+}$T-cells cultured with supernatants derived from co-cultures of MOLT-4 CD4 ${ }^{+}$T-cells and PBMCs from sample ZM09-99. In addition, RT enzyme activity was present in the supernatants of infected MOLT-4 and M8166 CD4 ${ }^{+}$T-cells with no RT activity detected in supernatants prepared from uninfected T-cells. Viral cDNA prepared from supernatants from persistently infected MOLT-4 CD4 ${ }^{+}$T-cells were subjected to 454 sequencing. Genome assembly identified low coverage regions which were resolved by Sanger sequencing and genomic termini were completed by RACE to obtain an SIVagm genome of 9,676 nucleotides (DDBJ Acc. No: LC114462).

In order to speciate the NHPs examined in the present study we sequenced the $c y t b$ gene derived from AGM and baboons. This identified the AGMs as Chlorocebus cynosuros (the malbrouck) on the basis of $99 \%$ nucleotide sequence identity for the top ranked hit following blastn searches and $97 \%$ identity to the second highest ranked hit, C. pygerythrus (the vervet). Speciation of the baboon samples was also performed by cytb sequencing and identified the NHP as Papio cynocephaleus (the yellow baboon) with $99 \%$ identity over the typing region and comparable nucleotide sequence identity with $P$. kindae (the Kinda baboon) which are considered conspecific baboon species.

The phylogenetic relationship of the complete genome of the new SIV (derived from human MOLT-4 $\mathrm{CD}^{+}$T-cell supernatants) with previously characterised SIV and HIV genomes is shown in Figure 1. On the basis of the speciation data from the AGMs, the malbrouck SIV was termed SIVagmMAL-ZMB and fell within the SIVagm clade and notably clustered basally from previously characterised SIVagmVER genomes and was also segregated from SIVagmSAB, SIVagmTAN and SIVagmGRI with high branching probability. The SIVagmMAL-ZMB genome was most closely related (79\% nucleotide sequence identity) to the SIVagmVERAGM155 (Genbank Acc. No. M29975), which was isolated from a vervet monkey imported from Kenya [27]. To estimate phylogenetic relationships further, phylogenies were created based on analysis of gag, pol, env and nef proteins (Figure 2a-d) and this also revealed comparable tree topologies to those for the whole genome nucleotide sequence analysis with the SIVagmMAL-ZMB viral proteins branching early in the clade to all previously characterised Kenyan and Ethiopian vervet monkey SIVs in all phylogenies with high bootstrap support.

The SIVagmMAL-ZMB genome contained the classic gag-pol-env gene arrangement and encoded the accessory proteins vif, vpr, tat and rev seen in all previously described SIVagm genomes. Comparisons of the proteins encoded in SIVagmMAL-ZMB to homologues from other SIV species confirmed the presence of three highly conserved functional motifs in the gag protein (517 aa) among known primate lentiviruses in the p6 domain implicated in viral budding: L-X-X-L-F near the C-terminus of $\mathrm{p}^{\text {gag }}{ }^{\text {, }}$, the dileucine motif D-X-A-X-XL-L previously found to associate with vpr in SIVagm and the highly conserved lentivirus motif P-T/S-A-P were present in SIVagmMAL-ZMB as L-N-S-L-F, D-P-A-K-K-L-L and P-S-A-P respectively. The SIVagmMAL-ZMB env protein (876 aa) contains 18 highly conserved cysteine residues present in all SIVs and six additional cysteine residues conserved in the group SIVagmSAB, SIVagmTAN and SIVagmGRI [13]. The cellular tropism of SIVs is largely determined by the env gp120 V3 loop which is 34 amino acids in SIVagmMAL-ZMB with the crown consisting of the motif M-A-G as seen in previously described SIVagm strains [28]. It should be noted that the SIVagmMAL-ZMB genome was obtained following propagation in MOLT-4 CD4 ${ }^{+}$T-cells and may contain mutations in the V3 loop of the gp120 region for adaptation to growth in human T-cells. Therefore, the V3 loop of the gp120 region was amplified and sequenced from splenic genomic DNA from sample ZM09-99 and compared to the corresponding region of SIVagmMAL-ZMB derived following T-cell culture. There were no mutations detected over the 34 amino acids between the two samples.

To evaluate RNA integrity in NHP spleen extracts, $\beta$-actin was examined in samples from each species which yielded overlapping ranges and comparable mean $\mathrm{Ct}$ values: AGM ( $\mathrm{n}=94$, $\beta$-actin $\mathrm{Ct}$ range 16.8-20.4, mean 18.4) and baboon samples ( $\mathrm{n}=105$, $\beta$-actin $\mathrm{Ct}$ range 16.9-23.0, mean 19.2). A specific SIVagmMALZMB real-time PCR assay was employed for screening AGM and baboon splenic RNA and detected viral RNA in three malbrouck monkey samples (3/94; 3.2\%) collected in Zambia in 2008 and 2009: ZM08-57 mean Ct 28.8, ZM09-99 mean Ct 23.8 and ZM09-100 mean Ct 24.6. ZM09-99 had the highest viral load and was also the sample from which the persistently infected SIVagmMAL-ZMB MOLT-4 CD4 ${ }^{+}$T-cell line was established. No baboon samples contained detectable SIVagmMAL-ZMB RNA (0/105; 0\%).

Surveillance of retroviruses in NHPs in several African countries have been performed, however, no surveillance from Zambia has been reported previously. Studies of SIV seroprevalence in baboons from Tanzania $(P$. ursinus) indicated low levels $(<1 \%)$ of antibody positivity to SIV [29], indicative of low levels of SIV infection in this species. A recent study of AGM populations in the wild, examined $C$. sabaeus from Gambia in West Africa and found high SIV seroprevalence (44\%) [30]. In a study in South Africa, SIV seroprevalence in vervet monkeys varied considerably between infants/juveniles (7\%) and adults $(68 \%)$ and between adult females (78\%) and males (57\%) [31]. This variation in seroprevalence rates between AGMs and 
baboons was also observed in a study of 11 NHP species in Cameroon which give reactivity rates of 0-52\% reflecting differing host, gender and age-specific susceptibilities to infection [32].

Development of non-invasive sampling methods for the characterisation of SIV in faecal and urine samples has stimulated studies of the natural history of SIV of endangered species such as chimpanzees, gorillas and bonobos [1]. The blood and spleen tissue samples collected from AGMs and yellow baboons in the present study were collected in 2008 and 2009 prior to the advent of these non-invasive sampling methodologies. These non-invasive sampling approaches have greatly boosted studies on the health and long-term survival by analysing the simian faecal virome [1]. Further studies in Zambia will focus on the development of these noninvasive sampling approaches to study the natural history of simian retroviruses in NHPs.

Ayouba and colleagues have highlighted that despite the fact that the six AGM species proposed by Groves [33] represent an important potential zoonotic reservoir of simian retroviruses for spillover into human populations, only eight complete genomes have been annotated: $C$. pygerythrus (vervet, $\mathrm{n}=4$ ), C. sabaeus (green monkey $\mathrm{n}=2$ ), C. tantalus (tantalus monkey, $\mathrm{n}=1$ ), C. aethiops (grivet, $\mathrm{n}=1$ ), $C$. djamdjamensis (Bale mountain vervet, $\mathrm{n}=0$ ) and $C$. cynosuros (malbrouck, $\mathrm{n}=0$ ) [19]. Given the broad distribution of AGMs across Africa, this study is the first to report an SIV genome from the malbrouck monkey. Our results may serve to improve our understanding of the evolutionary history of SIV in NHPs. Further studies are required to examine the prevalence of the newly described SIV in malbrouck, vervet and other AGM and NHP species elsewhere in Africa, the natural history of the agent, whether it impacts on fitness and what evidence exists, by use of specific serological assays, for exposure in human populations.

\section{Acknowledgements}

We would like to thank the Department of National Parks and Wildlife of the Ministry of Tourism and Arts (formerly ZAWA) for assistance with sample collection in Zambia. This study was supported in part by grants from the Ministry of Education, Culture, Sports, Science and Technology; the Ministry of Health, Labour and Welfare, Japan (MEXT)/JSPS KAKENHI; and the Japan Initiative for Global Research Network on Infectious Diseases (J-GRID), MEXT Japan.

\section{Conflict of Interest}

The authors declare that they have no conflicts of interest.

\section{References}

1. Peeters M, Delaporte E (2012) Simian retroviruses in African apes. Clin Microbiol Infec 18:514-520

2. Jin MJ, Rogers J, Phillips-Conroy JE, Allan JS, Desrosiers RC, Shaw GM, Sharp PM, Hahn BH (1994) Infection of a yellow baboon with simian immunodeficiency virus from African green monkeys: evidence for cross-species transmission in the wild. J Virol 68:8454-8460

3. Bailes E, Gao F, Bibollet-Ruche F, Courgnaud V, Peeters M, Marx PA, Hahn BH, Sharp PM (2003) Hybrid origin of SIV in chimpanzees. Science 300:1713

4. Huet T, Cheynier R, Meyerhans A, Roelants G, Wain-Hobson S (1990) Genetic organization of a chimpanzee lentivirus related to HIV-1. Nature 345:356-359

5. Santiago ML, Rodenburg CM, Kamenya S, Bibollet-Ruche F, Gao F, Bailes E, Meleth S, Soong SJ, Kilby JM, Moldoveanu Z, et al. (2002) SIVcpz in wild chimpanzees. Science 295:465

6. Van Heuverswyn F, Li Y, Neel C, Bailes E, Keele BF, Liu W, Loul S, Butel C, Liegeois F, Bienvenue Y, et al. (2006) Human immunodeficiency viruses: SIV infection in wild gorillas. Nature 444:164

7. Chen Z, Telfier P, Gettie A, Reed P, Zhang L, Ho DD, Marx PA (1996) Genetic characterization of new West African simian immunodeficiency virus SIVsm: geographic clustering of household-derived SIV strains with human immunodeficiency virus type 2 subtypes and genetically diverse viruses from a single feral sooty mangabey troop. J Virol 70:3617-3627

8. Tsujimoto H, Hasegawa A, Maki N, Fukasawa M, Miura T, Speidel S, Cooper RW, Moriyama EN, Gojobori T, Hayami M (1989) Sequence of a novel simian immunodeficiency virus from a wild-caught African mandrill. Nature 341:539-541

9. Beer BE, Bailes E, Goeken R, Dapolito G, Coulibaly C, Norley SG, Kurth R, Gautier JP, Gautier-Hion A, Vallet D, et al. (1999) Simian immunodeficiency virus (SIV) from sun-tailed monkeys (Cercopithecus solatus): evidence for host-dependent evolution of SIV within the C. lhoesti superspecies. J Virol 73:7734-7744

10. Hirsch VM, Campbell BJ, Bailes E, Goeken R, Brown C, Elkins WR, Axthelm M, Murphey-Corb M, Sharp PM (1999) Characterization of a novel simian immunodeficiency virus (SIV) from L'Hoest monkeys (Cercopithecus l'hoesti): implications for the origins of SIVmnd and other primate lentiviruses. J Virol 73:1036-1045

11. Hirsch VM, Dapolito GA, Goldstein S, McClure H, Emau P, Fultz PN, Isahakia M, Lenroot R, Myers G, Johnson PR (1993) A distinct African lentivirus from Sykes' monkeys. J Virol 67:1517-1528 
12. Courgnaud V, Pourrut X, Bibollet-Ruche F, Mpoudi-Ngole E, Bourgeois A, Delaporte E, Peeters M (2001) Characterization of a novel simian immunodeficiency virus from guereza colobus monkeys (Colobus guereza) in Cameroon: A new lineage in the nonhuman primate lentivirus family. J Virol 75:857-866

13. Lauck M, Switzer WM, Sibley SD, Hyeroba D, Tumukunde A, Weny G, Taylor B, Shankar A, Ting N, Chapman CA, et al. (2013) Discovery and full genome characterization of two highly divergent simian immunodeficiency viruses infecting black-and-white colobus monkeys (Colobus guereza) in Kibale National Park, Uganda. Retrovirology 10

14. Allan JS, Short M, Taylor ME, Su S, Hirsch VM, Johnson PR, Shaw GM, Hahn BH (1991) Species-specific diversity among simian immunodeficiency viruses from African green monkeys. J Virol 65:2816-2828

15. Fukasawa M, Miura T, Hasegawa A, Morikawa S, Tsujimoto H, Miki K, Kitamura T, Hayami M (1988) Sequence of simian immunodeficiency virus from African green monkey, a new member of the HIV/SIV group. Nature 333:457-461

16. Hirsch V, Riedel N, Kornfeld H, Kanki PJ, Essex M, Mullins JI (1986) Cross-reactivity to human Tlymphotropic virus type III/lymphadenopathy-associated virus and molecular cloning of simian T-cell lymphotropic virus type III from African green monkeys. Proc Natl Acad Sci U S A 83:9754-9758

17. Hirsch VM, McGann C, Dapolito G, Goldstein S, Ogen-Odoi A, Biryawaho B, Lakwo T, Johnson PR (1993) Identification of a new subgroup of SIVagm in tantalus monkeys. Virology 197:426-430

18. Ohta Y, Masuda T, Tsujimoto H, Ishikawa K, Kodama T, Morikawa S, Nakai M, Honjo S, Hayami M (1988) Isolation of simian immunodeficiency virus from African green monkeys and seroepidemiologic survey of the virus in various non-human primates. Int J Cancer 41:115-122

19. Ayouba A, Njouom R, Chia JE, Ahuka-Mundeke S, Kfutwah A, Ngole EM, Nerrienet E, Delaporte E, Peeters M (2015) Molecular characterization of a new mosaic Simian Immunodeficiency Virus in a naturally infected tantalus monkey (Chlorocebus tantalus) from Cameroon: A challenge to the virushost co-evolution of SIVagm in African green monkeys. Infect Genet Evol 30:65-73

20. Soares MA, Robertson DL, Hui H, Allan JS, Shaw GM, Hahn BH (1997) A full-length and replicationcompetent proviral clone of SIVAGM from tantalus monkeys. Virology 228:394-399

21. Chomba C, Senzota R, Chabwela H, Mwitwa J, Nyirenda V (2012) Patterns of Human-Wildlife Conflicts in Zambia: Causes, Consequences and Management Responses. Journal of Ecology and the Natural Environment 4:303-313

22. Sasaki M, Ishii A, Orba Y, Thomas Y, Hang'ombe BM, Moonga L, Mweene AS, Ogawa H, Nakamura I, Kimura T, et al. (2013) Human Parainfluenza Virus Type 3 in Wild Nonhuman Primates, Zambia. Emerg Infect Dis 19:1500-1503

23. Miura T, Sakuragi J, Kawamura M, Fukasawa M, Moriyama EN, Gojobori T, Ishikawa K, Mingle JAA, Nettey VBA, Akari H, et al. (1990) Establishment of a Phylogenetic Survey System for Aids-Related Lentiviruses and Demonstration of a New Hiv-2 Subgroup. Aids 4:1257-1261

24. Overbergh L, Kyama CM, Valckx D, Debrock S, Mwenda JM, Mathieu C, D'Hooghe T (2005) Validation of real-time RT-PCR assays for mRNA quantification in baboons. Cytokine 31:454-458

25. Katoh K, Standley DM (2013) MAFFT Multiple Sequence Alignment Software Version 7: Improvements in Performance and Usability. Mol Biol Evol 30:772-780

26. Ronquist F, Teslenko M, van der Mark P, Ayres DL, Darling A, Hohna S, Larget B, Liu L, Suchard MA, Huelsenbeck JP (2012) MrBayes 3.2: Efficient Bayesian Phylogenetic Inference and Model Choice Across a Large Model Space. Syst Biol 61:539-542

27. Johnson PR, Fomsgaard A, Allan J, Gravell M, London WT, Olmsted RA, Hirsch VM (1990) Simian immunodeficiency viruses from African green monkeys display unusual genetic diversity. J Virol 64:1086-1092

28. Pandrea I, Kornfeld C, Ploquin MJY, Apetrei C, Faye A, Rouquet P, Roques P, Simon F, Barre-Sinoussi F, Muller-Trutwin MC, et al. (2005) Impact of viral factors on very early in vivo replication profiles in simian immunodeficiency virus SIVagm-infected African green monkeys. J Virol 79:6249-6259

29. Kodama T, Silva DP, Daniel MD, Phillips-Conroy JE, Jolly CJ, Rogers J, Desrosiers RC (1989) Prevalence of antibodies to SIV in baboons in their native habitat. AIDS Res Hum Retroviruses 5:337-343

30. Ma DZ, Jasinska AJ, Feyertag F, Wijewardana V, Kristoff J, He TY, Raehtz K, Schmitt CA, Jung Y, Cramer JD, et al. (2014) Factors Associated with Siman Immunodeficiency Virus Transmission in a Natural African Nonhuman Primate Host in the Wild. J Virol 88:5687-5705

31. Ma DZ, Jasinska A, Kristoff J, Grobler JP, Turner T, Jung Y, Schmitt C, Raehtz K, Feyertag F, Sosa NM, et al. (2013) SIVagm Infection in Wild African Green Monkeys from South Africa: Epidemiology, Natural History, and Evolutionary Considerations. Plos Pathogens 9

32. Aghokeng AF, Liu W, Bibollet-Ruche F, Loul S, Mpoudi-Ngole E, Laurent C, Mwenda JM, Langat DK, Chege GK, McClure HM, et al. (2006) Widely varying SIV prevalence rates in naturally infected primate species from Cameroon. Virology 345:174-189

33. Wilson DE, Reeder DM (2005) Mammal species of the world: a taxonomic and geographic reference. JHU 
Figure Legends

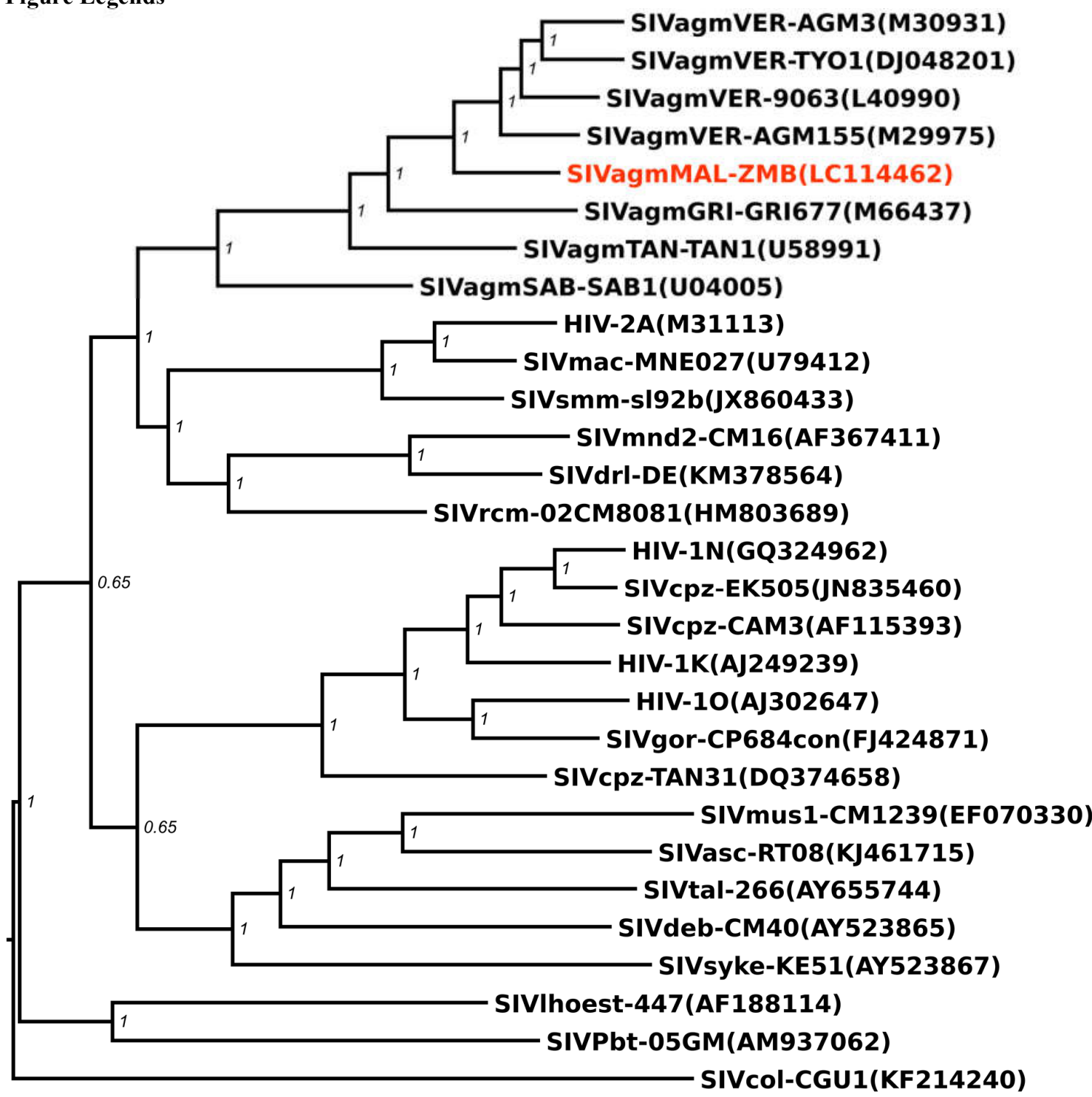

0.1

Figure 1. Phylogenetic tree of SIVagmMAL-ZMB genome and representative SIV genome sequences. The probability of the branching is shown next to the nodes. The tree is drawn to scale, with branch lengths measured in the number of substitutions per site. The scale bar represents a distance of 0.1 substitutions per site. SIVagmMAL-ZMB is coloured in red. 


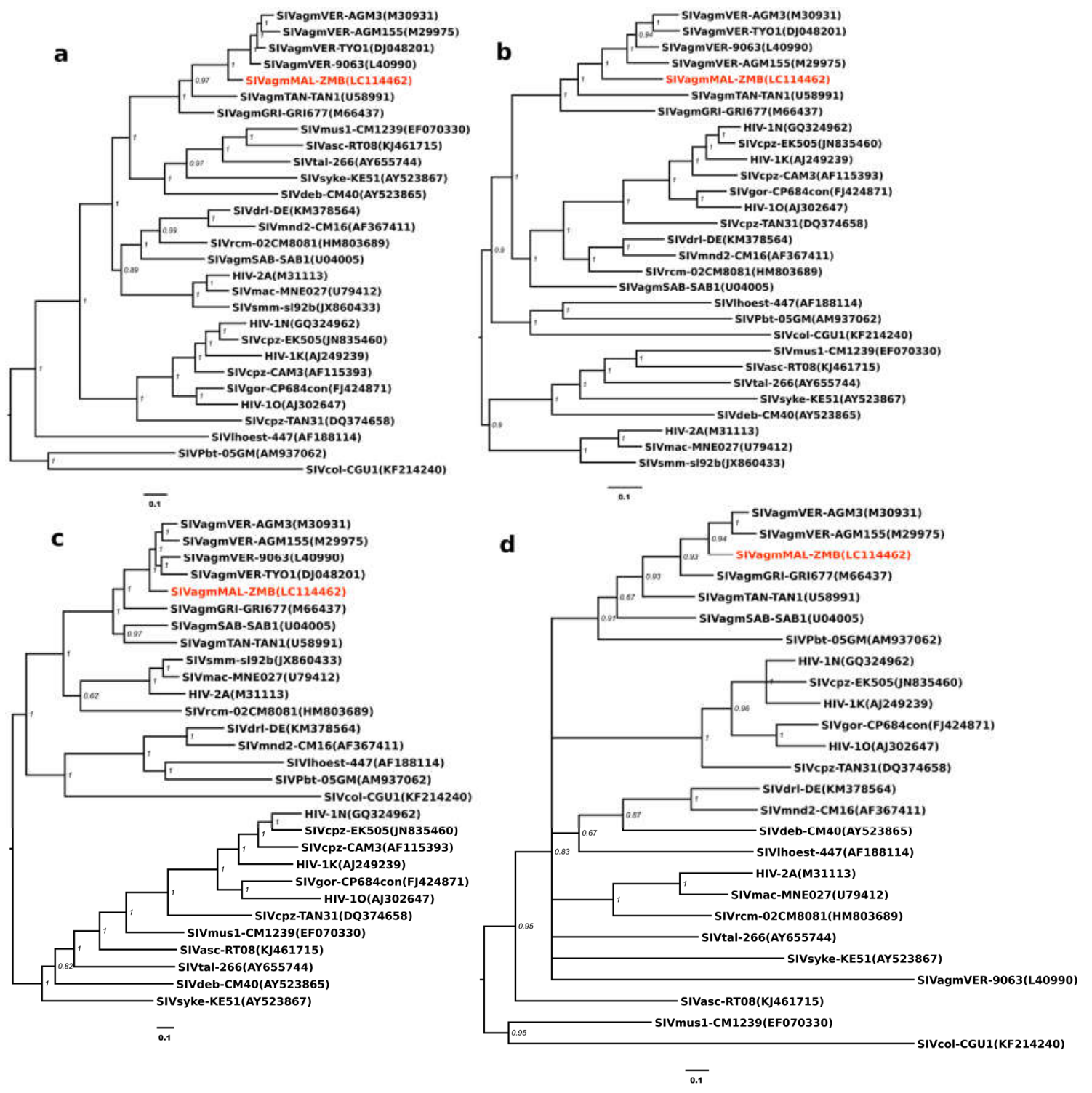

Figure 2. Phylogenetic analysis of the gag, pol, env and nef proteins encoded in the SIVagmMAL-ZMB genome. The probability of the branching is shown next to the nodes. The trees are drawn to scale, with branch lengths measured in the number of substitutions per site. The scale bars represent a distance of 0.1 substitutions per site. The SIVagmMAL-ZMB taxa is coloured in red. The trees correspond to a) gag protein b) pol protein c) env protein and d) nef protein. 